\title{
Type of Positive Interdependence and Affiliation Motive in an Asynchronous, Collaborative Learning Environment
}

\section{$\square$ Susan Brewer and James D. Klein}

In this study, we investigated the effect of type of positive interdependence (roles, rewards, roles-plus-rewards, or no structure) and affiliation motives (high vs. low) in an asynchronous, collaborative learning environment. College reentry students worked together in small, fully online discussion groups that lasted for seven days. Results indicated that participants in groups given roles plus rewards interacted with their teammates significantly more than those given rewards only or no-structured-interdependence conditions. A significant positive correlation suggested that participants with higher numbers of interactions attained higher posttest scores. However, no significant differences were found in achievement by type of interdependence or by affiliation motive. Results also revealed that type of interdependence and affiliation motive had a significant impact on student attitudes. Implications for integrating small group work in online higher education settings are discussed.

Keywords: Cooperative learning, positive interdependence, affiliation, social orientation, roles, rewards, online, asynchronous, distance learning

Over the past decade, there has been increased research on using small group methods with college students and other adult learners. According to Johnson, Johnson, and Smith (1998a), the results of this research are impressive when the magnitude of effect sizes in favor of cooperative over competitive and individual methods are considered. Furthermore, a meta-analysis of 39 studies in undergraduate settings points to significant positive effects of 
small group learning on achievement, persistence, and attitude (Springer, Stanne, \& Donovan, 1999). However, other researchers have found that small group learning does not always enhance college student performance (Cole \& Smith, 1993; Niehoff \& Mesch, 1991) especially when well-designed instruction is given to all participants (Klein, Erchul, \& Pridemore, 1994; Klein \& Schnackenberg, 2000). These mixed results indicate that there is still much to be learned about using small group methods with adults.

Even though the components of cooperative learning have been well defined, Cooper (1995) noted that systematic research on the efficacy of each is still quite scarce, particularly for college populations. Common to all explanations of what constitutes cooperative learning is the notion of positive interdependence. Positive interdependence (cooperation) results when students promote and facilitate each other's efforts to learn (Johnson, Johnson, \& Smith, 1998b). Earlier theorists (Deutsch, 1949; Kelly, 1957) differentiated two major categories of interdependence: outcome and means. Outcome interdependence includes goals and rewards; means interdependence includes resources, roles, and tasks. Student perceptions of goals and rewards influence the means they will use to accomplish the desired end state (Johnson \& Johnson, 1992). Addressing cooperative learning in the college setting, Johnson et al. Smith (1998a) suggested that instructors should structure positive interdependence so that every student senses a responsibility for learning the assigned materials and also for ensuring that all members of the group learn it. They also suggested that positive interdependence can be strengthened with joint rewards, divided resources, and complementary roles.

\section{Establishing Positive Interdependence} with Roles and Rewards

Frequently used in cooperative learning, role interdependence is defined in terms of how group members will interact. In some instances, the role of each group member is named by function. In other cases, group members are given a script or set of sequenced directions. In the broadest sense, role interdependence is established with interaction guidelines. The basic premise of role interdependence is that the members of the group need one another to complement their own roles within the group (Johnson \& Johnson, 1992). Several researchers have established that positive interdependence, created by providing roles, scripts, or structured interaction guidelines, has beneficial effects on achievement, attitude, and participant interaction (Cavalier, Klein, \& Cavalier, 1995; Hall et al., 1988; Klein \& Doran, 1999; McDonald, Larson, Dansereau, \& Spurlin, 1985; O’Donnell, Dansereau, Hall, \& Rocklin, 1987; Yadrick, Regian, Connolly-Gomez, \& Robertson-Schule, 1997). 
Another way to establish interdependence in cooperative settings is to provide rewards. According to Kagan (1992), rewards are a distinguishing factor between strong and weak forms of interdependence. Hays (1976) contended that reward interdependence largely explains the relationship between cooperation and achievement, because individuals will increase their achievement only if there is a specific group contingency reinforcing them for doing so. Furthermore, Slavin (1991) asserted that rewards are necessary to promote cooperation and motivation in small group settings. However, Kohn (1991) believed that the rewards for group work are counterproductive and can decrease, if not extinguish, intrinsic motivation. Regardless, there is some evidence that appropriate rewards have a positive impact on performance, attitude, and group processes when adult learners use cooperative learning methods (Cole \& Smith, 1993; Jensen, Johnson, \& Johnson, 2002; Joyce, 1999; O'Donnell 1996).

\section{Social Orientation and Cooperation}

Providing rewards for cooperation may only be necessary for students who aren't intrinsically motivated to work with others. At the root of small group learning, social interdependence theory assumes that cooperative efforts are based on intrinsic motivation generated by interpersonal factors and the desire to achieve a significant goal (Johnson, Johnson, \& Smith, 1998a). Under the broad term of social orientation, sources of intrinsic motivation include being part of a group, being valued by others, relatedness, affiliation, social adaptability, desiring communication, and extroversion (Digman, 1997; Huitt, 2001; Jackson, 1974; Leonard, Beauvais, \& Scholl, 1999; McClelland, 1976;). Social orientation is distinct from other factors that influence group and individual learning, such as cognitive ability, study skills, and affective states (Brewer \& Klein, 2004; Chan, 1980/1981; Dansereau \& Armstrong, 1986; Horn, Collier, Oxford, Bond, \& Dansereau, 1998; O'Donnell et al., 1987). Research on small group learning confirms that social orientation such as a student's affiliation motive has an impact on performance and attitudes in these settings (Chan, 1980 /1981; Hall et al., 1988; Klein \& Pridemore, 1992; Klein \& Schnackenberg, 2000).

\section{Small Group Learning in Distance Education}

Recently, the use of small group methods has been suggested in distance education settings to reduce anonymity and isolation (Hall, 1997). McIsaac and Gunawardena (1996) noted that computer-mediated communication facilitates group work among distance learners because it is time-independent and allows "many-to-many" interactive communication. Research on computer- 
mediated collaborative learning has indicated that it can be as effective (Johnston, 1996) or more effective (Hall, 1997; Naidu \& Oliver, 1999; Uribe, Klein, \& Sullivan, 2003) than face-to-face collaboration. Furthermore, the quantity (Ahern \& Repman, 1994; Hathorn \& Ingram, 2002) and quality (Camin, Glicken, Hall, Quarantillo, \& Merenstein, 2001; Hillman, 1999; Kruger, Cohen, Marca, \& Matthews, 1996) of interaction between learners in a computer-mediated environment may exceed that of a face-to-face environment.

Many of the recommendations for asynchronous online groups corroborate the findings for face-to-face small group work. Hathorn and Ingram (2002) noted that, although a computer interface may be designed for collaboration, simply putting students into groups is unlikely to result in collaboration by itself. They suggested that, without grades for collaborative effort, students will tend to use the most direct method of solving the problem or sharing the work. Additionally, there may be a general inclination to work individually or competitively, based on previous academic experience. Providing instructions on how to collaborate is recommended to overcome these potential pitfalls (Ahern \& Repman, 1994; Hathorn \& Ingram).

\section{Purpose of the Study}

The current study was designed to examine the effect of positive interdependence and affiliation motive on achievement, attitude, and interaction behavior for adult students in an asynchronous learning environment. The four treatment conditions were role, reward, role-plus-reward, and no structured interdependence. Groups were formed to include both high and low affiliation participants. Data were collected on posttest performance, attitudes, and interactions between group members. The research questions were:

1. What is the effect of type of positive interdependence on achievement, attitude, and interaction behavior for adult students in an asynchronous collaborative learning environment?

2. What is the relationship between affiliation motive and achievement, attitude, and quantity of interaction when adult students use an asynchronous collaborative learning environment?

3. Do positive interdependence and affiliation motive interact to affect achievement, attitude, and interaction behavior for adult students in an asynchronous collaborative learning environment?

Based on previous studies, we hypothesized that students who received structured interdependence would perform better and have better attitudes than those with no interdependence. We further hypothesized that students who received two types of interdependence would perform better than those 
who received only one type of interdependence. Finally we believed that students with high need for affiliation would have more positive attitudes and would interact more.

\section{METHOD}

\section{Participants}

Participants were 289 undergraduate business majors (104 males and 185 females) enrolled in a required course in management at a private degree completion university for adult learners. They ranged in age from 20 to 62, with a mean and median age of 35 and 34, respectively. The composition of the institution's student body indicates that $61 \%$ report their ethnicity as White, $18 \%$ as Black, and $11 \%$ as Hispanic. The reasons that students most frequently cite for attending this institution are that their life and work experiences are recognized, that they can put what they learn in the classroom to immediate use in the work environment, that class times and meeting places can be coordinated with their busy work schedules, and that they can participate in the learning process with other adults of varied, but comparable, experiences (Institution Fact Book, 2003).

Student participation was solicited by contacting course instructors who had agreed to act as facilitators. Students from 47 course sections participated on their own volition, with signed informed consent and without compensation. Students were informed that they would be working with students from other sections of the same course and that they would have structured exercises prior to the final exam. Furthermore, potential student participants were told that they could choose, without penalty, to submit a final paper representing their individual work if they did not want to be in the study. Group sample sizes were 30 to 42 , with an average of 36 participants in each treatment condition.

\section{Materials and Instruments}

Data collection instruments used in this study were an affiliation scale, online lectures, practice exercises, instructor notes, a posttest, an attitude measure, and an interaction checklist for categorizing group interaction in the online teams during practice periods. The affiliation scale of the Work Motivation Inventory (Braskamp \& Maehr, 1987) was used to measure affiliation motive. The scale contained 14 items that determine the degree to which an individual is motivated to affiliate with others. A 5-point Likert-type format was used to indicate whether or not a person agrees with statements such as "I work harder when I'm part of a team," and "I go out of my way to be friendly." Norms for the Spectrum-I version of the inventory were based on adults 18-79 
years, with $35.6 \%$ in the 26-35 year range. Internal consistency reliability of the affiliation scale is .84 . Raw scores are converted to $T$ scores, with a mean of 50 $(S D=10)$. In the current study, participant scores ranged from 18 to $70(M=$ $53.6, S D=6.4$ ). A median split was used to designate participants as high or low in affiliation motive, with raw scores of 53 and below indicating low, and 54 and above indicating high. There were 144 high affiliation and 145 low affiliation participants.

Materials for three instructional units were developed and pilot tested by the researchers. These materials were derived from the required course text, Management: Leading People and Organizations in the 21st Century (Dessler, 2001). Following standard policies for the institution, students were assigned readings from the textbook, and then received units consisting of an online lecture and practice materials posted by the course instructor. The units were on the topics of organizing human capital, Maslow's hierarchy of needs, and managing employee motivation. Each unit included a learning objective, a 500-750 word online lecture with an open-ended discussion starter, and a practice set. The practice set for each unit provided 10 selected-response items, including 8 items related to concepts and 2 application items related to a business or adult education scenario.

Instructor notes included a weekly schedule for delivering the sequentially numbered course components. The course components were the individual text-and-graphic files for the lectures, practice sets, and directive communications to the participants. The schedule provided information on the day each component was to be posted, the name of the restricted access folder in which the component was to be posted, the purpose of each component, and directions for an additional activity for the instructor to perform, such as attaching an extra file. The instructor notes also gave step-by-step directions on how to post the text-and-graphics files to the online newsgroups and provided a telephone number for assistance.

A posttest developed by the researchers was used to measure student achievement. In a previous implementation with the same target audience, the Cronbach's alpha internal consistency reliability of the posttest was .71; in the current study it was .65. A subject matter expert reviewed the posttest for content validity. The test consisted of 10 selected-response items for each of the three units, for a total of 30 items. The test form presented items grouped together by topics in the same order as the instructional sequence. The same 24 items related to concepts that were used in the practice sets also appeared on the posttest, but the response set for each item was presented in a different order. Six application items were different from the items in the practice sets, but were related to the same business or adult education scenarios presented in the practice sets. 
A 14-item survey was developed by the researchers to measure student attitude regarding the practice method experienced. The Cronbach's alpha internal consistency reliability of the attitude survey was .75. The survey contained 12 items such as "I benefited from working with others during these lessons"; "For this type of online group activity, I prefer that every member has an assigned role"; and "During this week, it was important to me that every team member earned a high score." A 5-point Likert-type scale prompted participants to respond to the items as being not at all true for me, slightly true, moderately true, mostly true, and very true. Additionally, 2 open-ended response items asked participants what they liked best and least about the way the learning team was structured for the week's activities.

An interaction checklist was adapted from instruments previously used to record observable group interactions in face-to-face settings (Hall et al., 1988; Cavalier, Klein, \& Cavalier, 1995; Klein \& Schnackenberg, 2000). Interaction in the current study was observed through the text transcripts of posts made by participants during group work. Adaptations of the predecessor instruments were made to reflect verbal behaviors that are likely to occur and can be demonstrated in an asynchronous collaborative learning environment through text and graphics (Hall, 1997; Hillman, 1999; Kruger et al., 1996). The interaction behaviors were qualitatively analyzed according to the three categories of (a) cognitive, (b) group process, and (c) off task. Cognitive interactions included statements about course topics, such as discussing content by providing examples or elaborating, asking questions, answering questions, and disputing others' opinions. Group process interactions included statements intended to accomplish a task by interpreting requirements or establishing due dates; managing group behavior by delegating, accepting, or declining responsibility; encouraging teammates; and commenting on the experimental project in which they were participating. Off task interactions included statements about topics not related to this course, such as discussing self or others in a context other than the class, and describing events not related to the course. A single post made by a student could contain more than one interaction behavior.

\section{Procedures}

All procedures took place in an asynchronous environment supported by Microsoft ${ }^{\mathrm{TM}}$ Outlook Express ${ }^{\circledR}$, which is the usual delivery modality for participants. Features of the user interface and the activities that take place are referenced with names that mimic typical classrooms. For example, when participants "go to class," they connect to the Internet and gain password protected access to files for their registered course. When participants "speak up in class," they submit a text message that is displayed chronologically with comments from other class members, available for all to read. The software 
interface organizes text-and-graphics messages into newsgroups named Main Classroom, Learning Team A, Learning Team B, and so forth. Furthermore, the software interface indents replies and subsequent comments, creating a visual representation of the interactions taking place. A topic of discussion shown with its associated dialogue is called a thread.

Participants communicated with one another by posting a message to either the Main Classroom newsgroup visible to all members of the class, or by posting a message to their Learning Team visible only to the small group members. This action is similar to sending an e-mail message, except that the recipient is a group of people rather than an individual. Participants were well oriented to using the software interface because it is the primary means of communication for all of their courses. Additionally, participants had been oriented to working in groups during a required course at entry to their academic programs. In this course, students read about teamwork, and build a learning charter, or contract, with fellow teammates that identifies each person's strengths and weaknesses, and also identify methods the team will use to resolve conflict, should it arise. Finally, the teamwork training includes coaching from the instructor with suggestions for establishing responsibilities and deadlines within the team. All undergraduate courses at this institution have group projects that comprise about $30 \%$ of the grade.

The study protocol was run six times, with each session accommodating an average of 20 triads. In order to make the transition from regular online classrooms to the new online locations for the study, participants were prompted with three messages posted in their regular classroom during the week prior to the study. These messages gave step-by-step technical instructions for the actions described as going to the virtual auditorium, meeting the instructor and new teammates for the upcoming week-long project, and getting acquainted in a private learning team room with a group of three students. In addition to the text instructions for gaining access to the new online locations, a designated toll-free number for assistance was established with the university's technical support call center. Students who had not logged in to the new online locations during the first 24 hours of the experimental period received a private e-mail and phone message advising them to join the newsgroup in order to maintain their required attendance for that course.

On the first and second days of the regular class, which was four weeks prior to beginning the study, participants completed the affiliation scale. They were blocked by high or low affiliation motive and randomly assigned to one of the four small group treatment conditions. The random assignment procedure also accounted for mixed triads with either one high-two low-affiliation members or one low-two high-affiliation members. Participants worked together in newly formed teams of three, meeting in private online groups des- 
ignated as cross-section learning teams. Participants in all treatment conditions were prompted that the discussion starters in each lecture were similar to the open-ended questions that they typically discuss in their courses at this institution. In addition to this implicit prompt for interaction at the end of each lecture, participants were given additional explicit directions for interaction that established the treatment conditions.

On Day 1 of the study, the project instructor welcomed the participants and initiated an ice-breaker activity. The project instructor also posted a script in each triad's newsgroup that provided guidelines for working in their small group. All scripts stated, "Throughout this week, use the lectures and practice sets to prepare for the test." Additionally, in the role interdependence condition, each group of three participants was directed to designate the roles of facilitator, answer drafter, and verifier for the group members. Groups were prompted to rotate roles for each unit. In the reward interdependence condition, each group of three participants was informed that it would receive a 5point (15\%) bonus toward the week's assignment if all members of the group attained a score of $24(80 \%)$ or more. In the role-plus-reward interdependence condition, each group of three participants was directed to designate roles, and was informed of the bonus points for all members of the group attaining a score of $80 \%$ or more. In the no-structured-interdependence condition, each group of three participants was informed only that they should discuss the readings and questions and use the practice sets to prepare for the test.

On Days 1,3, and 5 of the study, the project instructor posted the lecture and practice sets for Units 1, 2, and 3, respectively. These units were posted identically in the restricted access newsgroup for each small group of three participants. On Days 2, 4, and 6, participants worked in their respective small groups as directed by the scripted message for their treatment condition. On Day 7, all participants individually took an online posttest, which constituted their graded assignment for that week. Participants in all treatment conditions were told that the score they earned during the final assessment for this unit would be used as their weekly grade. In all treatment conditions, participants were directed to a password secured Web site to take an individual online posttest that was available for one hour in order to simulate a time-limited classroom setting.

\section{Design and Data Analysis}

A $4 \times 2$ factorial design was used with positive interdependence (Role, Reward, Role plus Reward, or No Interdependence), and affiliation motive (High or Low) as the independent variables. The dependent variables were achievement and attitude. Additionally, participant interactions were examined. 
Analysis of variance (ANOVA) was used to analyze posttest scores and effect sizes were calculated with $e t a^{2}$. Multivariate analysis of variance (MANOVA) was conducted on data from the attitude survey. Follow-up univariate analyses and Tukey's HSD pairwise comparisons were conducted on the individual attitude items if a significant effect was found, and effect sizes were calculated with Cohen's $d$. Qualitative analysis was used to identify common themes in the participant response to the open-ended attitude items about what participants liked most and least about their learning teams. The quantity of participant interaction was counted as the total messages posted by each learner within the learning team newsgroup. ANOVA was used to analyze quantity of interactions; correlation analysis was conducted to determine the relationship between quantity of interactions and posttest score. To be conservative, alpha was set at .01 for all statistical tests.

The nature of group interaction was examined by qualitatively analyzing messages among teammates. A sample of 40 out of 97 learning teams was selected at random, representing 10 triads in each treatment condition and a balance of high and low affiliation students. Preparation for qualitative analysis included a training session for the primary and two secondary raters, using the interaction checklist and data from triads that were not selected for analysis. Following the first training session, minor revisions were made to the checklist in order to clarify the meaning of the categories, and a second training session was held for the three raters. Inter-rater agreement was determined to be a fairly high .91. Chi-square analyses were then used to test these data for differences in the frequency of cognitive interactions, group process interactions, and off-task interactions between triads. The overall chi-square analysis was followed by pairwise comparisons among the four groups on the three major interaction categories of cognitive, group process, and off-task interactions.

\section{RESULTS}

\section{Achievement}

Table 1 provides means and standard deviations for achievement posttest scores. These results show that for all groups, the mean was 21.24, and was 21.79 for participants who worked in small groups with role interdependence, 21.18 for reward interdependence, 21.25 for role-plus-reward (both) interdependence, and 20.62 for participants who worked in small groups with no structured interdependence. The mean for participants with high affiliation was 21.47, and was 21.01 for participants with low affiliation. ANOVA did not show a main effect for type of interdependence $[F(3,281)=1.22, p=.30$, effect 
size $=.01]$, or affiliation motive $[F(1,281)=1.25, p=.26$, effect size $=.00]$, or any interaction effect $[F(3,281)=1.59, p=.19$, effect size $=.02]$.

\section{Attitude}

Table 2 shows means for responses to the attitude items by affiliation motive and type of interdependence. The $4 \times 2$ MANOVA did not reveal an interaction between affiliation motive and type of interdependence. MANOVA did reveal a significant overall effect for affiliation motive. Follow up univariate analyses revealed a significant effect on attitude item numbers $3,6,7,9,10$, and 12. In each of these cases, participants with high affiliation had significantly higher agreement with statements describing their small group experience ( $p$ $<.01)$. These items reflected benefit from working with others, ability to learn because of giving or receiving help from others, concern with the score and success of teammates, and preference for future activities that included points based on teammates' performance.

Additionally, the $4 \times 2$ MANOVA conducted on the 12 items revealed a significant overall effect for type of interdependence. Follow-up univariate analyses revealed a significant effect for type of interdependence on attitude item numbers $3,4,7,9$, and $10(p<.01)$. Results of pairwise comparisons using Tukey's HSD tests indicated that participants in the reward interdependence groups had significantly higher agreement than those in no-structured-interdependence groups with the following attitude statements:

Table $1 \square$ Means and standard deviations for achievement posttest scores by small group treatments and affiliation motive.

\begin{tabular}{|c|c|c|c|c|c|c|}
\hline & \multicolumn{6}{|c|}{ Type of Interdependence } \\
\hline \multicolumn{2}{|c|}{ Affiliation Motive } & Role & Reward & Both & None & Total \\
\hline High & $\begin{array}{c}M \\
S D\end{array}$ & $\begin{array}{c}22.40 \\
3.49 \\
(\mathrm{n}=35)\end{array}$ & $\begin{array}{c}21.95 \\
3.80 \\
(\mathrm{n}=38)\end{array}$ & $\begin{array}{c}20.97 \\
3.87 \\
(\mathrm{n}=41)\end{array}$ & $\begin{array}{c}20.47 \\
3.66 \\
(n=30)\end{array}$ & $\begin{array}{c}21.47 \\
3.76 \\
(\mathrm{n}=144)\end{array}$ \\
\hline Low & $\begin{array}{c}M \\
S D\end{array}$ & $\begin{array}{c}21.24 \\
3.48 \\
(\mathrm{n}=38)\end{array}$ & $\begin{array}{c}20.34 \\
3.77 \\
(\mathrm{n}=35)\end{array}$ & $\begin{array}{c}21.52 \\
3.49 \\
(\mathrm{n}=42)\end{array}$ & $\begin{array}{c}20.77 \\
3.37 \\
(\mathrm{n}=30)\end{array}$ & $\begin{array}{c}21.01 \\
3.53 \\
(n=145)\end{array}$ \\
\hline All & $\begin{array}{c}M \\
S D\end{array}$ & $\begin{array}{c}21.79 \\
3.51 \\
(n=73)\end{array}$ & $\begin{array}{c}21.18 \\
3.85 \\
(n=73)\end{array}$ & $\begin{array}{c}21.25 \\
3.67 \\
(n=83)\end{array}$ & $\begin{array}{c}20.62 \\
3.49 \\
(n=60)\end{array}$ & $\begin{array}{c}21.24 \\
3.64 \\
(n=289)\end{array}$ \\
\hline
\end{tabular}

${ }^{*}$ Note: Total possible score was 30 . 
Table $2 \square$ Means for attitude item responses by affiliation motive and small group treatments.

\begin{tabular}{|c|c|c|c|c|c|}
\hline \multirow[b]{2}{*}{$\#$} & \multirow[b]{2}{*}{ Response } & \multicolumn{4}{|c|}{ High Affiliation } \\
\hline & & Role & Reward & Both & None \\
\hline 1. & $\begin{array}{l}\text { I would have enjoyed this activity more if } \\
\text { I had worked by myself. }\end{array}$ & 1.38 & 1.65 & 1.90 & 1.77 \\
\hline 2. & $\begin{array}{l}\text { Working with other students in this type of } \\
\text { activity encourages me to stick with my } \\
\text { degree program. }\end{array}$ & 3.38 & 3.22 & 3.28 & 3.20 \\
\hline 3. & $\begin{array}{l}\text { I benefited from working with others } \\
\text { during these lessons. * }\end{array}$ & 3.88 & 3.32 & 3.87 & 3.20 \\
\hline 4. & $\begin{array}{l}\text { As a group, we generated better ideas than } \\
\text { we could have done as individuals. * }\end{array}$ & 3.53. & 3.54 & 3.72 & 3.30 \\
\hline 5. & $\begin{array}{l}\text { At the start of the week, I knew how to } \\
\text { interact with my team members. }\end{array}$ & 3.18 & 3.00 & 3.28 & 3.33 \\
\hline 6. & $\begin{array}{l}\text { I was able to learn more because I knew it } \\
\text { was my job to help the other team } \\
\text { members understand the material. }\end{array}$ & 3.21 & 2.84 & 3.33 & 2.97 \\
\hline 7. & $\begin{array}{l}\text { I was able to learn more because my team } \\
\text { members knew it was their job to contribute } \\
\text { to the group work.* }\end{array}$ & 3.15 & 3.05 & 3.33 & 2.73 \\
\hline 8. & $\begin{array}{l}\text { In future team activities, I would prefer } \\
\text { that each member of my team be assigned } \\
\text { specific roles. }\end{array}$ & 2.91 & 3.03 & 2.79 & 2.97 \\
\hline 9. & $\begin{array}{l}\text { During this week, it was important to me } \\
\text { that every team member earned a high score.* }\end{array}$ & 4.35 & 4.57 & 4.62 & 4.00 \\
\hline 10. & $\begin{array}{l}\text { For these lessons, it was important to me } \\
\text { that every member was highly successful.* }\end{array}$ & 4.38 & 4.62. & 4.49 & 3.97 \\
\hline 11. & $\begin{array}{l}\text { Thinking about my score on the final exam } \\
\text { helped me work with the team members. }\end{array}$ & 3.76 & 3.54 & 3.74 & 3.40 \\
\hline 12. & $\begin{array}{l}\text { In future team activities, I would prefer to } \\
\text { work for points based on my team members' } \\
\text { performance. }\end{array}$ & 2.32 & 2.24 & 2.79 & 2.30 \\
\hline
\end{tabular}




\begin{tabular}{|c|c|c|c|c|c|c|c|}
\hline \multicolumn{4}{|c|}{ Low Affiliation } & \multicolumn{4}{|c|}{ Total } \\
\hline Role & Reward & Both & None & Role & Reward & Both & None \\
\hline 2.13 & 1.45 & 2.07 & 1.66 & 1.78 & 1.60 & 1.99 & 1.70 \\
\hline 2.55 & 3.61 & 2.74 & 2.55 & 2.96 & 3.35 & 3.00 & 2.92 \\
\hline 3.08 & 3.70 & 3.00 & 2.38 & 3.46 & 3.50 & 3.42 & 2.80 \\
\hline 3.21 & 3.85 & 3.10 & 2.48 & 3.36 & 3.69 & 3.40 & 2.93 \\
\hline 2.97 & 3.12 & 2.95 & 2.86 & 3.05 & 3.05 & 3.09 & 3.10 \\
\hline 2.84 & 2.94 & 2.74 & 2.24 & 3.02 & 2.83 & 3.05 & 2.62 \\
\hline 2.87 & 3.06 & 2.64 & 1.90 & 3.00 & 3.06 & 2.98 & 2.32 \\
\hline 3.13 & 2.06 & 2.52 & 2.59 & 3.01 & 2.59 & 2.63 & 2.77 \\
\hline 3.66 & 4.55 & 4.17 & 3.48 & 3.99 & 4.56 & 4.39 & 3.75 \\
\hline 3.76 & 4.55 & 4.17 & 3.52 & 4.06 & 4.59 & 4.33 & 3.75 \\
\hline 3.34 & 3.79 & 3.40 & 2.66 & 3.56 & 3.62 & 3.56 & 3.07 \\
\hline 2.18 & 2.00 & 2.05 & 1.69 & 2.26 & 2.10 & 2.39 & 2.00 \\
\hline
\end{tabular}

Note: Likert-type scale for responses consisted of $5=$ Very true, $4=$ Mostly true, $3=$ Moderately true, $2=$ Slightly true, $1=$ Not true. $\quad$ *significant at $p<.01$. 
- "I benefited from working with others during these lessons," (effect size $=0.26$ ).

- "As a group, we generated better ideas than we could have done as individuals," and (effect size $=0.29$ ).

- "During this week, it was important to me that every team member earned a high score," (effect size $=0.41$ ).

Role-plus-reward interdependence groups had significantly higher agreement than those in no-structured-interdependence groups with the following attitude statement:

- "For these lessons, it was important to me that every member was highly successful," (effect size $=0.42$ ).

All three interdependence groups-role, reward, and role-plus-rewardhad significantly higher agreement than those in no-structured-interdependence groups with the following attitude statement:

- "I was able to learn more because my team members knew it was their job to contribute to the group work," (effect size range 0.26 to 0.28 ).

When asked "What did you like most about this week's activities?" the most frequent response ( $28 \%$ of all participants) referred to the group size, with comments such as "I liked that the group was small and intimate." The second most frequent response (26\%) referred to discussing the answers and getting clarification from teammates. This response was indicated with comments such as "Each team member was very willing to contribute. We had good debates and verified our information"; and "I liked how we can all answer the questions and compare with each other, then discuss why we felt the way we did." The third most frequent response (14\%) pointed to enjoying working with and meeting new people, with comments such as "I worked with people that were not in my previous class and I like to get to know as many people as possible, to hear their views on school and business in general"; and "It's a good experience to work with new teams because that's just how the real world expects us to be flexible."

When asked, "What did you like least about this week's activities?" the most frequent response (29\%) referred to wanting more or better directions, with comments such as "It would have been better to have had more detailed instructions and have them a couple days before the start of the project." The second most frequent response (14\%) was about teammates who did not contribute adequately. This response was indicated with comments such as "It is hard when all team members are not as motivated. I wanted to discuss things a bit more and have the input from the entire group, but that didn't seem to 
happen." The third most frequent response (12\%) indicated wanting to know the teammates better, with comments such as "I really didn't know them too well"; and "Not really knowing a lot about my teammates made it harder to have trust in their abilities."

\section{Participant Interactions}

During seven consecutive days of attending class in the asynchronous online environment, individual participants posted between 2 and 41 messages to their electronic newsgroups while working in their small groups. A $4 \times 2$ ANOVA on frequency of interaction revealed a significant main effect for type of interdependence $\left(p<.001, \eta^{2}=.07\right)$. Follow-up univariate analyses revealed that participants in groups with role-plus-reward interdependence $(M=18.34$ and $S D=.86$ ) had significantly more interactions than did those in either the reward $(M=13.57$ and $S D=.92)$ or none $(M=13.55$ and $S D=1.02)$ conditions. A correlation analysis conducted to determine the relationship between quantity of interactions and posttest score revealed a significant positive correlation, indicating that participants with higher numbers of interactions attained higher posttest scores $[r(289)=0.29, p<.001]$.

Table 3 shows the frequency of cognitive interactions, group process interactions, and off-task interactions for a sample of 40 small groups. Cognitive interactions included statements about course topics, such as discussing content by providing examples or elaborating, asking questions, answering questions, and disputing others' opinions. Group process interactions included statements intended to accomplish a task by interpreting requirements or establishing due dates; managing group behavior by delegating, accepting, or

Table $3 \square$ Frequency and nature of group interactions by small group treatments.

\begin{tabular}{lrrrr}
\hline & \multicolumn{4}{c}{ Type of Interdependence } \\
\hline & Role & Reward & Both & None \\
\hline Cognitive Interactions* & 260 & 270 & 303 & 362 \\
Group Process Interactions* & 220 & 157 & 261 & 172 \\
Off Task Interactions* & 15 & 35 & 16 & 19
\end{tabular}

Note: Frequencies represent total interactions by 10 triad-groups in each treatment.

Total $=40$ triads. $\quad$ *Significant at $p<.01$. 
declining responsibility; encouraging teammates; and commenting on the project in which they were participating. Chi-square analysis revealed significant differences in each of the three categories of interactions. Follow-up pairwise comparisons revealed that groups with no structured interdependence had significantly more cognitive interactions than did role groups, $\left[\chi^{2}(1, N=\right.$ $20)=16.73, p<.001$, effect size $=0.84]$, and significantly more cognitive interactions than did reward groups $\left[\chi^{2}(1, N=20)=13.39, p<.01\right.$, effect size $\left.=0.67\right]$.

In addition, groups with role interdependence had significantly more group process interactions when compared to those with only reward interdependence $\left[\chi^{2}(1, N=20)=10.53, p<.01\right.$, effect size $\left.=0.53\right]$. Furthermore, groups with role-plus-reward (both) interdependence had significantly more group process interactions than did reward groups $\left[\chi^{2}(1, N=20)=25.88, p<.001\right.$, effect size $=1.29$ ].

Finally, groups with reward interdependence had significantly more offtask interactions than did groups with role interdependence $\left[\chi^{2}(1, N=20)=8\right.$, $p<.01$, effect size $=0.40]$ and role-plus-reward interdependence $\left[\chi^{2}(1, N=20)\right.$ $=7.08, p<.01$, effect size $=0.35$ ]. Table 4 summarizes significant findings by small group treatment and provides examples of cognitive, group process, and off-task interactions.

\section{DISCUSSION}

The purpose of this study was to investigate the effect of positive interdependence and affiliation motive in an asynchronous, collaborative learning environment. Adult reentry students received instruction and communicated with each other in small discussion groups in a fully online setting. Each small group was assigned to a treatment condition where positive interdependence was structured by providing roles, rewards, or roles-plus-rewards, or to a control group with no structured interdependence. Each small group included participants with both high and low affiliation motives.

\section{Achievement}

Participants in each of the small group conditions performed similarly on the posttest, with no significant differences by type of interdependence or affiliation motive. There are several possible reasons for this result. Although positive interdependence was structured in various ways in this study, other elements of cooperative learning were present in all treatments. Participants in all small groups had individual accountability and computer-mediated promotive interaction. Furthermore, while group facilitation skills and evaluation of interpersonal and group processes were not specifically directed in the cur- 
Table $4 \square$ Summary of results on nature of interactions by small group treatments.

\begin{tabular}{|c|c|c|c|}
\hline Treatment & Result & $\begin{array}{c}\text { Type of } \\
\text { Interaction }\end{array}$ & Sample comment \\
\hline
\end{tabular}

Role Role interdependence Group I'm not sure if we are going to be able to groups had more group Process count on a third team member. Let's process interactions than proceed as follows. Whether we get a did reward groups. ${ }^{*} \quad$ response from R. or not we need to complete all questions, of which 8 have already been verified. Finally, the summary needs to be completed, which I'll do tonight.

Reward Reward interdependence groups had more off task behaviors than did role and role-plus-reward interdependence groups.*

Both Role-plus-reward (both) interdependence groups had more group process interactions than did the reward group.*

None No structured interdependence groups had more cognitive interactions than reward only or role only groups.*

Off Task Thanks, J., a lot of rain here also, but my flowers needed it. I'm hoping the humidity drops.

Group Process

Here's my thought towards session 2. Open for discussion of course. Please post the unit 1 final answers, I didn't quite finish moving my oldest two daughters to Baltimore. I won't be back online until after 6 PM EDT. Thanks in advance.

Cognitive To an outsider, it would seem that you work for a division of $X Y Z$. Not being an expert on XYZ, I know they provide many services, e.g. disaster relief, fund raising. It would be conceivable to consider your organization a functional structure. What do think?

Note: Interactions by 10 triad-groups in each treatment.

*Significant at $p<.01$.

rent study, participants had previously been trained on these and other elements of cooperative learning. In fact, all students who enroll at the university where the study was implemented are trained on how to collaborate at the start of their degree program.

In addition, the instructional materials used by all participants were designed with stated objectives and alignment of the lesson content, practice exercises, and posttest. Others have indicated that compared to individual learning strategies, small group methods may not increase achievement when well-designed instruction is used by all learners (Bossert, 1988-1989; Klein \& Pridemore, 1992; Klein \& Schnackenberg, 2000). The current study suggests that the effect of structuring positive interdependence is likely to be weak when well-designed instructional materials are used. However, positive inter- 
dependence may influence outcomes when test instruments measure performance on higher order performance tasks.

\section{Attitude}

Positive interdependence is the "subjective experience of being on the same side" (Kagan \& Kagan, 1994, p. 129). In this study, participants' subjective experiences differed according to type of positive interdependence. Students given rewards felt that they benefited from working with others and that they generated better ideas as a group than they could have done as individuals. This finding corroborates previous research indicating that offering a bonus when all members exceed a standard reward increases the perception of positive interdependence and reduces social loafing (Johnson, Johnson, \& Holubec, 1994; Webb, 1997). Furthermore, concern for teammate success was apparently facilitated by reward structures. Attitude statements regarding the importance of team members earning a high score and every member being highly successful were significantly higher for participants in both conditions given rewards. This finding lends support to Slavin's (1991) assertion that group rewards are essential to eliciting concern for teammate achievement.

The effect of role interdependence in this study is demonstrated in the responses to the attitude statement, "I was able to learn more because my team members knew it was their job to contribute to the group work." Previous research points to increased learner satisfaction when defined roles are provided to small groups (Cavalier et al., 1995; O'Donnell et al., 1987). However, the impact of role interdependence on attitude should be viewed concurrently with the finding that student reward groups had significantly higher agreement with the item than those in the no-structured-interdependence groups.

When differences in attitude are examined by affiliation motive, participants with high affiliation had significantly more agreement than those with low affiliation with 6 of the 12 attitude statements. This result may be reflective of a general preference for group work, as noted in previous research on affiliation motive in small group work (Brewer, Klein, \& Mann, 2003; Chan, 1980/1981; Hall et al., 1988; Klein \& Schnackenberg, 2000;). Likewise, high affiliation participants' agreement with attitude statements may be reflective of a personality trait, or predisposition to act cooperatively (Huitt, 2001; Johnson et al., 1998a; McClelland, 1976). The finding that high affiliation participants had significantly higher endorsement of various aspects of group work, taken together with no significant differences in performance, underscores the distinctness of social orientation and cognitive ability noted in previous research (Chan, 1980/1981; Dansereau \& Armstrong, 1986; Hall et al., 1988; O’Donnell et al., 1987). 
Participant Interactions

It appears that there is an advantage to using multiple avenues of interdependence for increasing interactions. Participants in groups with role-plusreward interdependence had significantly more interactions than those in groups with reward interdependence or no structured interdependence. Furthermore, the significant positive correlation between achievement and number of interactions suggests that participants might have scored higher on the posttest if they had interacted more. Alternatively, there is a possibility that students with higher ability characteristically interact more.

Surprisingly, this study did not demonstrate a significant difference in number of interactions by affiliation motive. This finding is in contrast to earlier observations that high affiliation students interact more than those with low affiliation (Klein \& Schnackenberg, 2000) and that social orientation is associated with communication in groups (Hall et al., 1988). One explanation for this discrepancy may be found in previous research indicating that shy students are more likely to express themselves in computer-mediated communication, compared to face-to-face situations (Davis \& Ralph, 2001; Mabrito, 1991; Mason, 1989). Another explanation is that the use of median split in the current study did not adequately differentiate between high and low affiliation motives.

Turning to the substance of group interactions, there were significant differences in the frequency of certain types of interactions according to interdependence structures. Groups with no structured interdependence had significantly more cognitive interactions than did those with role or reward interdependence. Without guidelines on how to interact with one another, and without a specific incentive for generating communication, these participants spent their time together engaged in asking and answering questions and discussing the content. Moreover, the pattern of a leader asking an initial question and group members responding with answers may be the preferred or default method of conducting discussion in an asynchronous environment (Hall, 1997).

On the other hand, when role interdependence was used in the current study, participants exhibited more group process interactions. More specifically, the increased interactions in the role interdependence groups focused on managing task requirements and individual responsibilities, confirming that students generally do what they are told to do (Klein \& Doran, 1999). Hall (1997) maintained that students in computer-mediated environments, even more than other distance education students, need to be guided by a schedule of events. In the current study, the use of rotating roles for each unit may have provided such a schedule, but the benefit to student achievement and attitude was not demonstrated. 
Implications

The present sample was representative of the target population of adult reentry students, and implications are directed at that group of students. The attitude findings in this study support the recommendation to use small groups with adult reentry students. Overall, participants did not want to work alone; this preference for group work, even when there is no increased achievement, has been previously demonstrated in other studies (Brewer et al., 2003; Klein \& Doran, 1999; Klein \& Pridemore, 1992; Palincsar \& Brown, 1989; Thompson \& Scheckley, 1997).

Interaction between students is a vital component in an asynchronous, computer-mediated environment (Bailey \& Luetkehans, 1998; Gunawardena, 1995). In the absence of visual, auditory, and tactile communication cues, textbased interactions constitute the entirety of online communication (Hsu \& Sammons, 1998). Educators and instructional designers should provide structures that maximize meaningful exchanges among participants. Yet, beyond merely increasing the frequency of interactions, consideration should be given to the nature of these interactions. The cooperative behavior of taking turns does not exist in an asynchronous environment where the messaging software delivers participants' contributions in the time-stamped order in which they arrived. Even when messages are displayed together for a single topic, the synchronous quality of having an utterance associated with the one immediately preceding it, and the feedback loop provided therein, does not exist in computer-mediated communications (Hillman, 1999). Therefore, assigning roles for beginning and ending conversations may be beneficial.

The finding that participants with no structured interdependence had significantly more cognitive interactions than either role only or reward only is noteworthy for educators. When teachers of adult learners use group work, they should ensure that there is opportunity for students to ask and answer questions within the groups. Moreover, it may be less necessary for an instructor to structure positive interdependence when other elements of cooperative learning are present.

\section{Further Research}

Research should continue to investigate the quantity and nature of interactions in asynchronous, computer-mediated environments. Specifically, studies should be conducted to determine whether increasing interactions, or increasing particular types of interactions, is beneficial to learning and persistence. Also, the relationship between interactions and ability should be explored. 
Future research on affiliation motive in small group work may clarify whether the higher attitude ratings found in this study were reflective of a general preference for group work by high affiliation adults, or if group settings do indeed provide an optimal environment for some learners, but not for others. The current study did not compare group versus individual work in the asynchronous online environment, and this aspect should be examined in future studies, focusing on both achievement and attitude.

In light of the growing prevalence of online distance programs for adult learners, it is worthwhile to continue exploring whether previous assumptions about cooperative learning in face-to-face environments are replicated in asynchronous, computer-mediated, and distance learning settings. Research of this type may help us better understand the conditions under which cooperative learning is most effective for adults in online environments.

Susan Brewer is Program Assessment Manager at the University of Phoenix.

James D. Klein is Professor of Educational Technology at Arizona State University.

\section{REFERENCES}

Ahern, T. C., \& Repman, J. (1994). The effects of technology on online education. Journal of Research on Computing in Education, 537-547.

Bailey, M. L., \& Luetkehans, L. (1998, August). Ten great tips for facilitating virtual learning teams. Paper presented at the 14th Annual Conference on Distance Teaching and Learning, Madison, WI.

Bossert, S. T. (1988/1989). Cooperative activities in the classroom. In E. Z. Rothkopf (Ed.), Review of research in education (pp. 225-250). Washington, DC: American Educational Research Association.

Braskamp, L. A., \& Maehr, M. L. (1987). Work motivation inventory. Champaign, IL: Metritech.

Brewer, S., \& Klein, J. D (2004). Small Group Learning in an Online Asynchronous Environment. Paper presented at the national conference of the Association of Educational Communications and Technology, Chicago, Illinois.

Brewer, S., Klein, J. D., \& Mann, K. E. (2003). Using small group strategies with adult reentry students. College Student Journal, 37(2), 286-297.

Camin, C., Glicken, A., Hall, M., Quarantillo, B., \& Merenstein, G. (2001). Evaluation of electronic discussion groups as a teaching/learning strategy in an evidence-based medicine course: A pilot study. Education for Health: Change in Learning and Practice, 14(1), 21.

Cavalier, J. C., Klein, J. D., \& Cavalier, F. J. (1995). Effects of cooperative learning on performance, attitude, and group behaviors in a technical team environment. Educational Technology Research and Development, 43(3), 61-71.

Chan, R. M. (1980/1981). The effect of student need for affiliation on performance and satisfaction in group learning. Interchange, 11, 39-46.

Cole, B. C., \& Smith, D. L. (1993). Cooperative learning strategies for teaching adult business English. Journal of Education for Business, 68(3), 170-173. 
Cooper, J. L. (1995). Cooperative learning and critical thinking. Teaching of Psychology, 22(1), 7-8.

Davis, M., \& Ralph, S. (2001). Stalling the learning process: Group dynamics in cyberspace. Studies in the Education of Adults, 33(2), 217-229.

Dansereau, D. F., \& Armstrong, D. R. (1986). Evaluation of a verbal report inventory through script memory and learning strategies research. The Journal of Experimental Education, 54(Spring), 129-133.

Dessler, G. (2001). Management: Leading people and organizations in the 21st century. Upper Saddle River, NJ: Prentice Hall.

Deutsch, M. (1949). An experimental study of the effects of cooperation and competition upon group process. Human Relations, 2, 199-232.

Digman, J. M. (1997). Higher-order factors of the big five. Journal of Personality and Social Psychology, 73, 1246-1256.

Gunawardena, C. N. (1995). Social presence theory and implications for interaction and collaborative learning in computer conferences. International Journal of Educational Telecommunications, 1(3), 147-166.

Hall, D. (1997). Computer mediated communication in post-compulsory teacher education. Open Learning, 12(3), 54-56.

Hall, R. H., Rocklin, T. R., Dansereau, D. F., Skaggs, L. P., O’Donnell, A. M., Lambiotte, J. G., et al. (1988). The role of individual differences in cooperative learning of technical material. Journal of Educational Psychology, 80(2), 172-178.

Hathorn, L. G., \& Ingram, A. L. (2002, January/February). Online collaboration: Making it work. Educational Technology, 33-40.

Hays, L. (1976). The use of group contingencies for behavior control: A review. Psychological Bulletin, 91, 517-539.

Hillman, D. C. A. (1999). A new method for analyzing patterns of interaction. The American Journal of Distance Education, 13(2), 37-47.

Horn, E. M., Collier, W. G., Oxford, J. A., Bond, C. F., \& Dansereau, D. F. (1998). Individual differences in dyadic cooperative learning. Journal of Educational Psychology, 90(1), 153-161.

Hsu, S., \& Sammons, M. (1998, August 5-7, 1998). The Invisible barriers in teaching at a distance. Paper presented at the 14th Annual Conference on Distance Teaching and Learning, Madison, WI.

Huitt, W. (2001, April). Sources of motivational needs. Retrieved 12/8/2002 from http://chiron.valdosta.edu/whuitt/col/motivation/motivate.html

Institution Fact Book. (2003). http:/ / www.phoenix.edu/factbookweb/

Jackson, D. N. (1974). Personality research form manual. Goshen, NY: Research Psychologists Press.

Jensen, M. S., Johnson, D. W., \& Johnson, R. T. (2002). Impact of positive interdependence during electronic quizzes on discourse and achievement. The Journal of Educational Research, 95(3), 161-166.

Johnson, D. W., \& Johnson, R. T. (1992). Positive interdependence: Key to effective cooperation. In N. Miller \& R. Hertz-Lazarowitz (Eds.), Interaction in cooperative groups: The theoretical anatomy of group learning (pp. 174-199). New York: Cambridge University Press.

Johnson, D. W., Johnson, R. T., \& Holubec, E. J. (1994). The nuts \& bolts of cooperative learning. Edina, $\mathrm{MN}$ : Interaction Book Company.

Johnson, D. W., Johnson, R. T., \& Smith, K. A. (1998b, February). Maximizing instruction through cooperative learning. ASEE Prism, 7, 24-29. 
Johnson, D. W., Johnson, R. T., \& Smith, K. A. (1998b). Cooperative learning returns to college: What evidence is there that it works? Change, 30(4), 26-36.

Johnston, V. L. (1996). Toward a global classroom using computer-mediated communications at UAA. University of Alaska Anchorage. Vocational Teacher Education Research Report (Eric document \# ED356759)

Joyce, W. B. (1999). Cooperative learning in accounting classes: A case study. Business Education Forum, 54(1), 28-30.

Kagan, S. (1992). Cooperative learning. San Juan Capistrano, CA: Resources for Teachers, Inc.

Kagan, S., \& Kagan, M. (1994). The structural approach: Six keys to cooperative learning. In S. Sharan (Ed.), Handbook of cooperative learning methods (pp. 115-137). Westport, CT: Greenwood Press.

Kelly, T. (1957). George Birkbeck: Pioneer of Adult Education. Liverpool, England: Liverpool University Press.

Klein, J. D., \& Doran, M. S. (1999). Implementing individual and small group learning structures with a computer simulation. Educational Technology Research and Development, 47(1), 97-110.

Klein, J. D., Erchul, J. A., \& Pridemore, D. R. (1994). Effects of individual versus cooperative learning and type of reward on performance and continuing motivation. Contemporary Educational Psychology, 19, 24-32.

Klein, J. D., \& Pridemore, D. R. (1992). Effects of cooperative learning and need for affiliation on performance, time on task, and satisfaction. Educational Technology Research and Development, 40(4), 1042-1629.

Klein, J. D., \& Schnackenberg, H. L. (2000). Effects of informal cooperative learning and the affiliation motive on achievement, attitude, and student interactions. Contemporary Educational Psychology, 25, 332-341.

Kohn, A. (1991, February). Group grade grubbing versus cooperative learning. Educational Leadership, 48, 83-87.

Kruger, L. J., Cohen, S., Marca, D., \& Matthews, L. (1996). Using the Internet to extend training in team problem solving. Behavior Research Methods, Instruments and Computers, 28(2), 248-253.

Leonard, N. H., Beauvais, L. L., \& Scholl, R. W. (1999). Work motivation: The incorporation of self based processes. Human Relations, 52, 969-998.

Mabrito, M. (1991). Electronic mail as a vehicle for peer response. Written Communication, 8(4), 509-532.

Mason, R. (1989). An evaluation of CoSy on an Open University course. In

R. Mason \& A. Kaye (Eds.), Mindweave: Communication, computers and distance education. Oxford: Pergamon Press.

McClelland, D. C. (1976). The achieving society. New York: Irvington Publishers.

McDonald, B. A., Larson, C. O., Dansereau, D. F., \& Spurlin, J. E. (1985). Cooperative dyads: Impact on text learning and transfer. Contemporary Educational Psychology, 10, 369-377.

McIsaac, M. S., \& Gunawardena., C. N. (1996). Distance education. In D. H. Jonassen (Ed.), Handbook of research for educational communications and technology (pp. 403-437). New York: Simon \& Schuster Macmillan.

Naidu, S., \& Oliver, M. (1999). Critical incident-based computer supported collaborative learning. Instructional Science, 27(5), 329-354. 
Niehoff, B. P., \& Mesch, D. J. (1991). Effects of reward structures on academic performance and group processes in a classroom setting. The Journal of Psychology, 125(4), 457-467.

O'Donnell, A. M. (1996, March). Effects of explicit incentives on scripted and unscripted cooperation. Journal of Educational Psychology, 88, 74-86.

O'Donnell, A. M., Dansereau, D. F., Hall, R. H., \& Rocklin, T. R. (1987). Cognitive, social/affective, and metacognitive outcomes of scripted cooperative learning. Journal of Educational Psychology, 79(4), 431-437.

Palincsar, A. S., \& Brown, A. L. (1989). Classroom dialogues and promoting self-regulated comprehension. In J. Brophy (Ed.), Advances in research on teaching (pp. 35-71). New York: JAI.

Slavin, R. (1990). Research on cooperative learning: Consensus and controversy. Educational Leadership, 47(4), 52-55.

Slavin, R. E. (1991). Group rewards make groupwork work. Educational Leadership, 48(5), 89-91.

Springer, L., Stanne, M. E., \& Donovan, S. S. (1999). Effects of small-group learning on undergraduates in science, mathematics, engineering, and technology: A meta-analysis. Review of Educational Research, 69(1), 21-51.

Thompson, C., \& Scheckley, B. G. (1997). Differences in classroom teaching preferences between traditional and adult BSN students. Journal of Nursing Education, 36, 163-170.

Uribe, D., Klein, J. D., \& Sullivan, H. (2003). The effect of computer mediated collaborative learning on solving ill-defined problems. Educational Technology Research and Development, 51(1), 5-19.

Webb, N. M. (1997). Assessing students in small collaborative groups. Theory into Practice, 36, 205-213.

Yadrick, R. M., Regian, J. W., Connolly-Gomez, C., \& Robertson-Schule, L. (1997). Dyadic vs. individual practice with exploratory and directive mathematics tutors. Journal of Educational Computing Research, 17(2), 165-186. 


\section{COPYRIGHT INFORMATION}

TITLE: Type of Positive Interdependence and Affiliation Motive in an Asynchronous, Collaborative Learning Environment SOURCE: Educ Technol Res Devrk Jon 54 no4/312/12 Ag 20066062004

The magazine publisher is the copyright holder of this article and it is reproduced with permission. Further reproduction of this article in violation of the copyright is prohibited. 